\title{
Synthesis of polyferromethylsiloxane sorbents using a sol-gel method
}

\author{
Yuriy Leonidovych Zub a,b, Herbert W. Roesky b,: , Mariana Mykolaivna Malyar ${ }^{\text {c, }}$ \\ Alexei Alexeyevich Chuiko ${ }^{\mathrm{c}}$, Mietek Jaroniec ${ }^{\mathrm{d}}$, Ramaswamy Murugavel b,e \\ a Department of Chemistry, University of Kyiv-Mohyla Academy, 2, Skovoroda Str., 04070 Kyiv, Ukraine \\ ${ }^{\mathrm{b}}$ Institut für Anorganische Chemie der Universität Göttingen Tammannstrasse 4, D-37077 Göttingen, Germany \\ ${ }^{\mathrm{c}}$ Institute of Surface Chemistry of NAS of Ukraine, 31, Prospekt Nauky, 03680 Kyiv, Ukraine \\ ${ }^{\mathrm{d}}$ Department of Chemistry, Kent State University, Kent, OH 44242, USA \\ ${ }^{\mathrm{e}}$ Department of Chemistry, Indian Institute of Technology-Bombay, Mumbai-400 076, India
}

\begin{abstract}
Trivalent iron complexes which could be easily converted into materials are formed by the reaction of $\mathrm{FeCl}_{3}$ with $\mathrm{K}_{3}\left[\mathrm{O}_{3} \mathrm{SiMe}\right]$ in a highly concentrated aqueous alkaline solution. The presence of the liquid glass as an additive and decreasing the $\mathrm{pH}$ results in solutions that give rise to homogeneous gels. Polycondensation proceeds very rapidly in the higher $\mathrm{pH}$ range (viz. $\mathrm{pH}$ 9-10) and substantially slower in an acidic medium ( $\mathrm{pH} 2-3$ ). Xerogels were obtained having microporous structure after treatment of polyferromethylsiloxane gels obtained from acidic medium or mesoporous structure when obtained from alkaline medium.
\end{abstract}

Keywords: Iron(III); Methylsiloxane; Polycondensation

\section{Introduction}

The main interest in the area of developing new materials for adsorption is to have designed selectivity, which could be either a) geometrical selectivity: to distinguish between various structures due to the presence of pores of certain size and shapes, or b) chemical selectivity: caused by the reactions with functional groups present on the surface of the material. There are a number of very well studied and executed methods for constructing materials for geometrical adsorption selectivity which is based on the ability of the adsorbents to give a typical porous structure [1-6]. There are also a number of methods for chemical modification, which involve preparing the surface functional groups involving a complex and many-stage syntheses [7-9]. However, simultaneous creation of a preassigned porous structure and the introduction of desired functional groups (adsorption sites) would lead to the preparation of some exotic structures [10], one such method would be sol-gel technique [11].

There have been two different areas in which the polysiloxane material synthesis has advanced:

1. one of the areas is to synthesize functionalized polysiloxanes using multi silanol systems (i.e. using silanols with different functionalities) $[12,13]$. 
2. the second aim is to prepare porous doped organosiloxanes which involves that during a sol-gel transformation a heteroatom is introduced into the siloxane matrix, and this atom forms an active adsorption site [14].

In both these cases the choice of parameters such as $\mathrm{pH}$ of the medium, time of the gel aging, conditions of washing and drying, etc. allows one to produce sorbents with preassigned structure-adsorption characteristics. The second approach is more promising owing to the possibility of introducing heteroatoms with diverse properties as probable adsorption sites [15], along with an opportunity for varying the nature of organic groups on the silicon atom. Following these lines, a number of attempts have been already made to study gelation of sodium dihydroxy-methylsiliconate $\left(\mathrm{Na}\left[\mathrm{O}(\mathrm{OH})_{2} \mathrm{SiMe}\right]\right)$ and salts of metal ions such as $\mathrm{Mg}(\mathrm{II}), \mathrm{Co}(\mathrm{II}), \mathrm{Ni}(\mathrm{II})$, $\mathrm{Cu}(\mathrm{II}), \mathrm{Al}(\mathrm{III}), \mathrm{Ti}(\mathrm{IV})$, or $\mathrm{Zr}(\mathrm{IV})$ at alkaline $\mathrm{pH}$ in aqueous solutions [16-21]. However these investigations offer very little insight into the synthesis aspect. The sorbents prepared in an acidic medium were undurable and, often, chalk-like. Most of the sorbents have a low metal content in spite of the presence of excess metal salt during the synthesis and washing such a gel often led to a substantial depletion of the metal [22]. In addition, many samples of sorbents have a relatively low specific surface. The use of aqueous solutions in the above-mentioned work is warranted for industrial applications. However, owing to the fact that organosilanols are weak acids, and their alkali metal salts in aqueous solutions undergo hydrolysis, they result in formation of a strongly alkaline medium. Thus, the salts of transition metals would precipitate as of metal hydroxides under such reaction conditions. A similar problem has also been seen in the chemistry of inorganic silicates. Therefore, the gel-like products described in the literature [16-21] can contain both the organosiliconate fragments of metal complexes but also metalfree polyorganosiloxanes and silicon-free hydroxo(oxo) clusters of metals.

At the same time it is known that the ligands such as organosilanols $\left(\mathrm{R}_{3} \mathrm{SiO}^{-}\right)$, silanediols $\left(\mathrm{R}_{2} \mathrm{SiO}_{2}^{2-}\right)$, and silanetriols $\left(\mathrm{RSiO}_{3}^{3-}\right)$ form a variety of coordination compounds of metals in non-aqueous medium [23,24]. The molecular structures of this kind can model fragments of a number of promising catalysts $[25,26]$, novel materials for electronics [27,28], as well as fragments of the aforementioned adsorbents.
These studies have laid the foundation for development of substances with preassigned properties [24]. Therefore, the aim of this work is to combine these approaches to clone a synthesis method of new specific adsorbents on the basis of metal complexes having organosiliconate ligands. Among all the silanoates, $\left[\mathrm{RSiO}_{3}\right]^{3-}$ arouses the greatest interest due to its structural polyfunctionality. It has been found to be a good representative of compounds that form polymeric-porous structures and contain metal ions.

This paper describes the synthesis of polyferromethylsiloxane sorbents, with the synthesis based on a sol-gel method and involving $\mathrm{Fe}(\mathrm{III})$ complexes that are formed in an alkaline medium with the $\left[\mathrm{MeSiO}_{3}\right]^{3-}$ ligand.

\section{Experimental section}

\subsection{General}

\subsubsection{Materials}

The following materials obtained from commercial sources have been used without any further purification: methyltriethoxysilane $\left(\mathrm{C}_{2} \mathrm{H}_{5} \mathrm{O}\right)_{3} \mathrm{SiMe}$ (MTES) (98\% purity) (ABCR), liquid soda glass (40 wt \%; $d=1.415 \mathrm{~g} \mathrm{~cm}^{-3}$; silica modulus: $\mathrm{SiO}_{2} / \mathrm{Na}_{2} \mathrm{O}=2.86$ ), aqueous solution of sodium methylsiliconate $\mathrm{Na}\left[\mathrm{O}(\mathrm{HO})_{2} \mathrm{SiMe}\right]\left(30 \mathrm{wt} \%\right.$; ABCR), $\mathrm{FeCl}_{3} \cdot 6 \mathrm{H}_{2} \mathrm{O}(>$ $99 \%$; Merck), $\quad \mathrm{AlCl}_{3} \cdot 6 \mathrm{H}_{2} \mathrm{O} \quad(>99 \% ; \quad$ Aldrich), $\mathrm{ZrOCl}_{2} \cdot 6 \mathrm{H}_{2} \mathrm{O}$ (>99\%; Merck), cation-exchange resin KU-2 in an acidic form (FSU; fraction with granule sizes from 0.5 to $1.0 \mathrm{~mm}$; proton content in the dry resin: $3.5 \mathrm{mg} \cdot$ equiv $^{-\mathrm{g}^{-1}}$ ).

\subsubsection{Techniques}

The $\mathrm{pH}$ of the solutions has been controlled both during the synthesis as well as potentiometric titrations using an universal ionometer EV-74 (FSU). Elemental analysis of the samples (for $\mathrm{C}, \mathrm{H}, \mathrm{Fe}, \mathrm{K}$, $\mathrm{Na}, \mathrm{Si}$ ) have been measured at the Analytical Laboratory (Institute of Inorganic Chemistry, University of Goettingen). The thermal analysis curves were recorded on Q-1500 D (MOM, Hungary) in the temperature range of $20-1000{ }^{\circ} \mathrm{C}$ (heating rate was equal to $\left.5{ }^{\circ} \mathrm{C} \mathrm{min}^{-1}\right)$. The structural-adsorption characteristics have been determined by the processing of the BET [29] and BJH [30] isotherms of adsorption-desorption of nitrogen recorded on an ASAP-2400 instrument (All the samples were previ- 
ously degassed at $200^{\circ} \mathrm{C}$ ). FTIR spectra were measured on Bio-Rad FTS-7; the samples were prepared in the form of tablets with calcined $\mathrm{KBr}$. EPR spectra were recorded on a SE/X-2543 instrument (RADIOPAN) at room temperature and at $77 \mathrm{~K}$. NMR spectra were recorded on Bruker AM 200 and Bruker AM 250 instruments. Chemical shifts are reported in sigma scale with reference to external $\mathrm{SiMe}_{4}$.

\subsubsection{Preparation of an aqueous solution of} potassium methylsiliconate, $\mathrm{K}_{3}\left[\mathrm{O}_{3} \mathrm{SiMe}\right]$

$\mathrm{KOH}(210.0 \mathrm{~g}, 10 \mathrm{~mol})$ was dissolved in $150 \mathrm{~mL}$ of water (in a water-cooled Erlenmeyer flask) to which MTES ( $89.0 \mathrm{~g}, 98 \mathrm{~mL}, 0.5 \mathrm{~mol})$ was added gradually under continuous stirring. After stirring the reaction mixture for $2 \mathrm{~h}$, a clear solution was obtained. The reaction mixture was heated till the ethanol was removed completely, during the distillation the volume of the mixture was maintained $200 \mathrm{~mL}$ by adding water periodically. The distillation was effected up to the solution temperature of $117^{\circ} \mathrm{C}$. After cooling the solution was diluted to $250 \mathrm{~mL}$ to obtain a $2 \mathrm{M}$ solution of potassium methylsiliconate.

\subsubsection{Preparation of polyferromethylsiloxane sorbent} (PFMS-A) using an acidic medium

A solution of $\mathrm{K}_{3}\left[\mathrm{O}_{3} \mathrm{SiMe}\right](15 \mathrm{~mL}, 2 \mathrm{M})$ was taken in a $150 \mathrm{~mL}$ beaker to which a solution of $\mathrm{FeCl}_{3}(15$ $\mathrm{mL}, 1 \mathrm{M}$ ) was added gradually under continuous stirring. The beaker along with the reaction mixture was weighed, and heated under stirring for $15 \mathrm{~min}$ on a water bath (at $90{ }^{\circ} \mathrm{C}$ ) until the initial precipitate got dissolved to give a clear transparent deep redbrown solution. The solution was cooled and diluted with water so that the weight of the beaker was maintained constant. To this solution, liquid glass (4.5 mL diluted with $12 \mathrm{~mL}$ of water) was added. The beaker with the reaction mixture was weighed again and then heated on a water bath for further 10 min. After cooling, the mixture was diluted once again to maintain a constant initial weight. The solution obtained was cooled in an ice bath down to $0{ }^{\circ} \mathrm{C}$.

The cation-exchange resin (17.0 g) was dispersed in water $(7.0 \mathrm{~mL})$. After absorption of water the swelled resin was cooled to $-15^{\circ} \mathrm{C}$. The frozen resin was introduced into the beaker containing the above cooled solution. The whole mixture, after stirring together rigorously for $4 \mathrm{~min}$ and maintaining the beaker temperature close to $0{ }^{\circ} \mathrm{C}$, was immediately filtered. The $\mathrm{pH}$ of the filtrate was 2.2. In $2 \mathrm{~h}$ the solution was converted to a homogeneous gel, with the completion of the conversion being accompanied with a strong opalescence. In $24 \mathrm{~h}$ the gel was subjected to centrifuging and multiple washing with water by decanting. Then it was filtered and dried for $72 \mathrm{~h}$ at room temperature in air. The air-dried dark-brown product $3.1 \mathrm{~g}$ by weight was finely powdered so that it could pass through a sieve with a mesh diameter of $0.25 \mathrm{~mm}$ and separated into two fractions: $0.10-0.25 \mathrm{~mm}$ and $<0.1 \mathrm{~mm}$.

\subsubsection{Preparation of polyferromethylsiloxane sorbent (PFMS-B) using a basic medium}

A solution of iron(III) methylsiliconate was prepared following the procedure described for the PFMS-A sample, to which liquid glass $(4.5 \mathrm{~mL}$ mixed with $4.5 \mathrm{~mL}$ of water) was added. The solution obtained was cooled in an ice bath to $0{ }^{\circ} \mathrm{C}$ and a solution of hydrochloric acid $(10.25 \mathrm{~mL}$ of $5 \mathrm{M})$ was added rapidly under rigorous mixing. The temperature of the mixture was raised to $10{ }^{\circ} \mathrm{C}$; and the $\mathrm{pH}$ of the solution amounted to $9.0 \pm 0.5$. In about 1 min a clear homogeneous gel was formed, as seen from the slight opalescence of the resultant mixture. The gel was let to stay at room temperature for $1 \mathrm{~h}$, following which it was subjected to centrifuging and multiple washing with water by decanting, and drying for $72 \mathrm{~h}$ at room temperature. The air-dried dark-brown product $6.0 \mathrm{~g}$ by weight was powdered and separated into fractions as described for the previous synthesis.

\section{Results and discussion}

Potassium methylsiliconate, one of the starting materials used has been prepared by hydrolysis of MTES in an aqueous $\mathrm{KOH}$ solution by maintaining the concentration. The resultant solution so formed is strongly basic (with $\mathrm{pH}$ in the range 13-14 depending on the concentration). Nevertheless, since the conjugate acids of alkylsilanolate anions are quite weak, some degree of hydrolysis is always observed even in strong concentrated alkaline media. The hydrolysis products are known to further undergo a self-condensation, for example:

$\left[\mathrm{O}_{3} \mathrm{SiMe}\right]^{3-}+\mathrm{H}_{2} \mathrm{O} \rightarrow\left[\mathrm{O}_{2}(\mathrm{OH}) \mathrm{SiMe}^{2-}+\mathrm{OH}^{-}\right.$ 
$2\left[\mathrm{O}_{2}(\mathrm{OH}) \mathrm{SiMe}^{2-} \rightarrow\left[\mathrm{O}_{2}(\mathrm{Me}) \mathrm{Si}-\mathrm{O}-\mathrm{Si}(\mathrm{Me}) \mathrm{O}_{2}\right]^{4-}+\mathrm{H}_{2} \mathrm{O}\right.$

Thus, the solution may contain oligomeric anions with different structures. This agrees with the ${ }^{13} \mathrm{C}$ and ${ }^{29} \mathrm{Si}$ NMR spectra of such solutions. The ${ }^{29} \mathrm{Si}$ NMR spectrum for a potassium methylsiliconate solution obtained immediately after introduction of MTES into $10 \mathrm{M} \mathrm{KOH}$ is presented in Fig. 1a.

It is seen that in the solution there are structural units of several types, with one type being markedly predominant with a signal at $-44.6 \mathrm{ppm}$ which correspond to $\left[\mathrm{MeSiO}_{3}\right]^{3-}$ anions. Such an assignment is in agreement with the literature values [31]. The remaining two weak signals of different intensity $(-51.1$ and $-52.2 \mathrm{ppm})$ can be attributed to the products of hydrolysis and condensation of methylsiliconate anions. After distillation of ethanol from the starting solution the latter contains an insignificant amount of oligomers (Fig. 1b). Fig. 2 shows also the ${ }^{29} \mathrm{Si}$ NMR spectrum for a solution of $\mathrm{Na}\left[\mathrm{O}(\mathrm{HO})_{2} \mathrm{SiMe}\right]$ for comparison.

It is evident that this solution contains a higher number of species. Besides, it is more prone to hydrolysis and (poly)condensation, which is evidenced by the ${ }^{29} \mathrm{Si}$ NMR spectrum for a solution of $\mathrm{K}\left[\mathrm{O}(\mathrm{HO})_{2} \mathrm{SiMe}\right]$ (Fig. 1c) recorded after a nondurable heating. (Note that the $\mathrm{K}\left[\mathrm{O}(\mathrm{HO})_{2} \mathrm{SiMe}\right]$ solution was prepared in the way similar to that applied to obtain the $\mathrm{K}_{3}\left[\mathrm{O}_{3} \mathrm{SiMe}\right]$ solution.) The comparison of the above-mentioned data sets gives strong evidence for the fact that it would be more preferable to use the solution of $\mathrm{K}_{3}\left[\mathrm{O}_{3} \mathrm{SiMe}\right]$ as a starting reagent.

These observations also match with the ${ }^{13} \mathrm{C}$ NMR spectra of these solutions. The signal at $-1.2 \mathrm{ppm}$ in the ${ }^{13} \mathrm{C}$ NMR spectrum (see Fig. 3a, b) can be ascribed to monomeric $\left[\mathrm{MeSiO}_{3}\right]^{3-}$ anions, while the second signal $(-1.1 \mathrm{ppm})$, can be attributed to products of their hydrolysis.

In view of the fact that this solution was used subsequently for reactions of hydrolytic polycondensation, the presence of hydrolyzed species however does not prevent from using the above-mentioned solution. The ${ }^{13} \mathrm{C}$ NMR spectrum for a solution of $\mathrm{K}\left[\mathrm{O}(\mathrm{HO})_{2} \mathrm{SiMe}\right]$ recorded after its heating (Fig. 3c) presents a rather complex pattern. It is evident not only from its comparison with the ${ }^{13} \mathrm{C}$ NMR spectrum for a solution of $\mathrm{K}_{3}\left[\mathrm{O}_{3} \mathrm{SiMe}\right]$ (Fig. $3 b$ ) but also from its comparison with the ${ }^{13} \mathrm{C}$ NMR spectrum for a solution of $\mathrm{Na}\left[\mathrm{O}(\mathrm{HO})_{2} \mathrm{SiMe}\right]$ (Fig. 2). As it was already mentioned, the application of such a solution would lead to unjustified complications in interpreting the achieved results.

The next step was the preparation of the solution containing the metal complexes. Addition of a solution of $\mathrm{K}_{3}\left[\mathrm{O}_{3} \mathrm{SiMe}\right]$ to a solution of $\mathrm{FeCl}_{3}$ at a molar ratio of 2:1 initially leads to the formation of a precipitate which easily dissolved upon heating on a water bath, resulting in the formation of a bright red-brown solution. It should be noted that in the case of the initial solution of $\mathrm{AlCl}_{3}$ the precipitate formed at the beginning of the process undergoes dissolution immediately upon mixing, while in the case of the initial solution of $\mathrm{ZrOCl}_{2}$ (with a molar ratio of reactants equal to 1:4) it is necessary to heat the mixture on a water bath (as in the case of $\mathrm{FeCl}_{3}$ ), but now the heating must be longer (up to $4 \mathrm{~h}$ ). In the case of the aluminum salt it is possible to assume that the dissolution of the precipitate is caused by formation of soluble hydroxocomplexes, whereas $\mathrm{Fe}(\mathrm{OH})_{3}$ and $\mathrm{Zr}(\mathrm{OH})_{4}$ are not soluble in aqueous alkaline solutions. Here one can make an assumption that the dissolution of the precipitates is caused by formation of methylsiliconate complexes of these metals. In a simpler case they may have a composition shown in scheme (3):

$\mathrm{M}^{n+}+x\left[\mathrm{MeSiO}_{3}\right]^{3-} \rightarrow\left[\mathrm{M}\left(\mathrm{O}_{3} \mathrm{SiMe}\right)_{x}\right]^{(3 x-n)-}$

This assumption is in agreement with the ${ }^{29} \mathrm{Si}$ and ${ }^{13} \mathrm{C}$ NMR spectra of the zirconium(IV) complexes. In the case of the ${ }^{29} \mathrm{Si}$ NMR spectra the shift of the signal $\Delta \delta_{\mathrm{Si}}$ (in comparison with its position in the spectrum for the solution of the $\mathrm{K}_{3}\left[\mathrm{O}_{3} \mathrm{SiMe}\right]$ salt) is equal to $2.0 \mathrm{ppm}$, and in the case of ${ }^{13} \mathrm{C} \mathrm{NMR}$ spectrum, the $\Delta \delta_{\mathrm{C}}$ amounts to $0.8 \mathrm{ppm}$ (Fig. 4), indicating the formation of polynuclear methylsiliconate complexes.

Neutralization of a solution of potassium ferromethylsiliconate (whose empirical formula provides an admissible evidence for $\mathrm{Si}: \mathrm{Fe}=2$ ) with hydrochloric acid gives rise to gelation, but the gelation is not homogeneous. In order to study the behavior of the system at various values of $\mathrm{pH}$, we performed a potentiometric titration with hydrochloric acid both for the initial solution of $\mathrm{K}_{3}\left[\mathrm{O}_{3} \mathrm{SiMe}\right]$ and for a solution containing methylsiliconate $\mathrm{Fe}(\mathrm{III})$ complexes at various concentrations of the above-mentioned substances. 


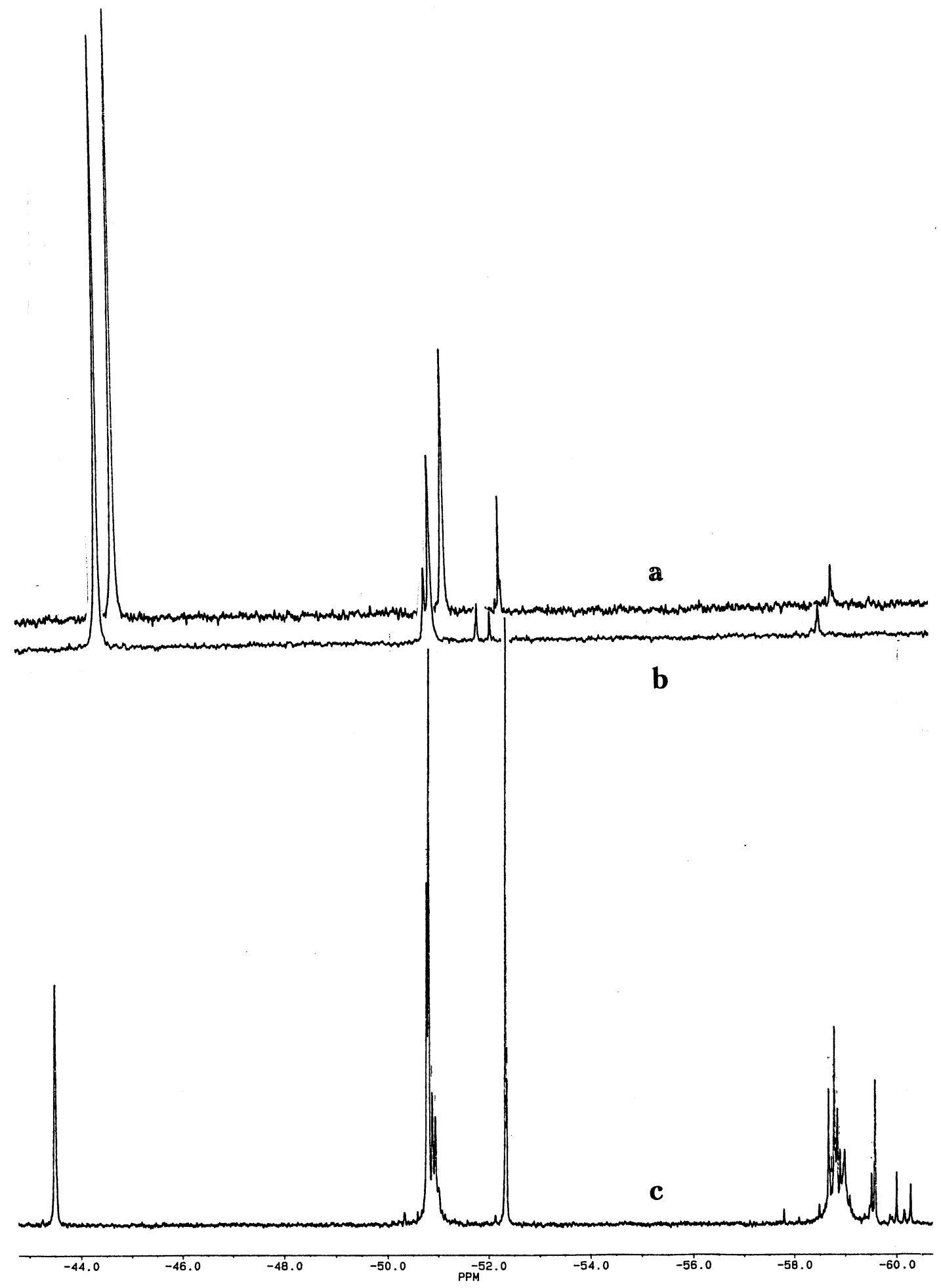

Fig. $1 .{ }^{29} \mathrm{Si} \mathrm{NMR}$ spectra for $\mathrm{K}_{3}\left[\mathrm{O}_{3} \mathrm{SiMe}\right]$ and $\mathrm{K}\left[\mathrm{O}(\mathrm{HO})_{2} \mathrm{SiMe}\right]$ solutions. a: $\mathrm{K}_{3}\left[\mathrm{O}_{3} \mathrm{SiMe}\right]$ solution prepared immediately after hydrolysis of MTES; b: $\mathrm{K}_{3}\left[\mathrm{O}_{3} \mathrm{SiMe}\right]$ solution after distillation of ethanol; $\mathbf{c}$ : $\mathrm{K}\left[\mathrm{O}(\mathrm{HO})_{2} \mathrm{SiMe}\right]$ solution after heating. 


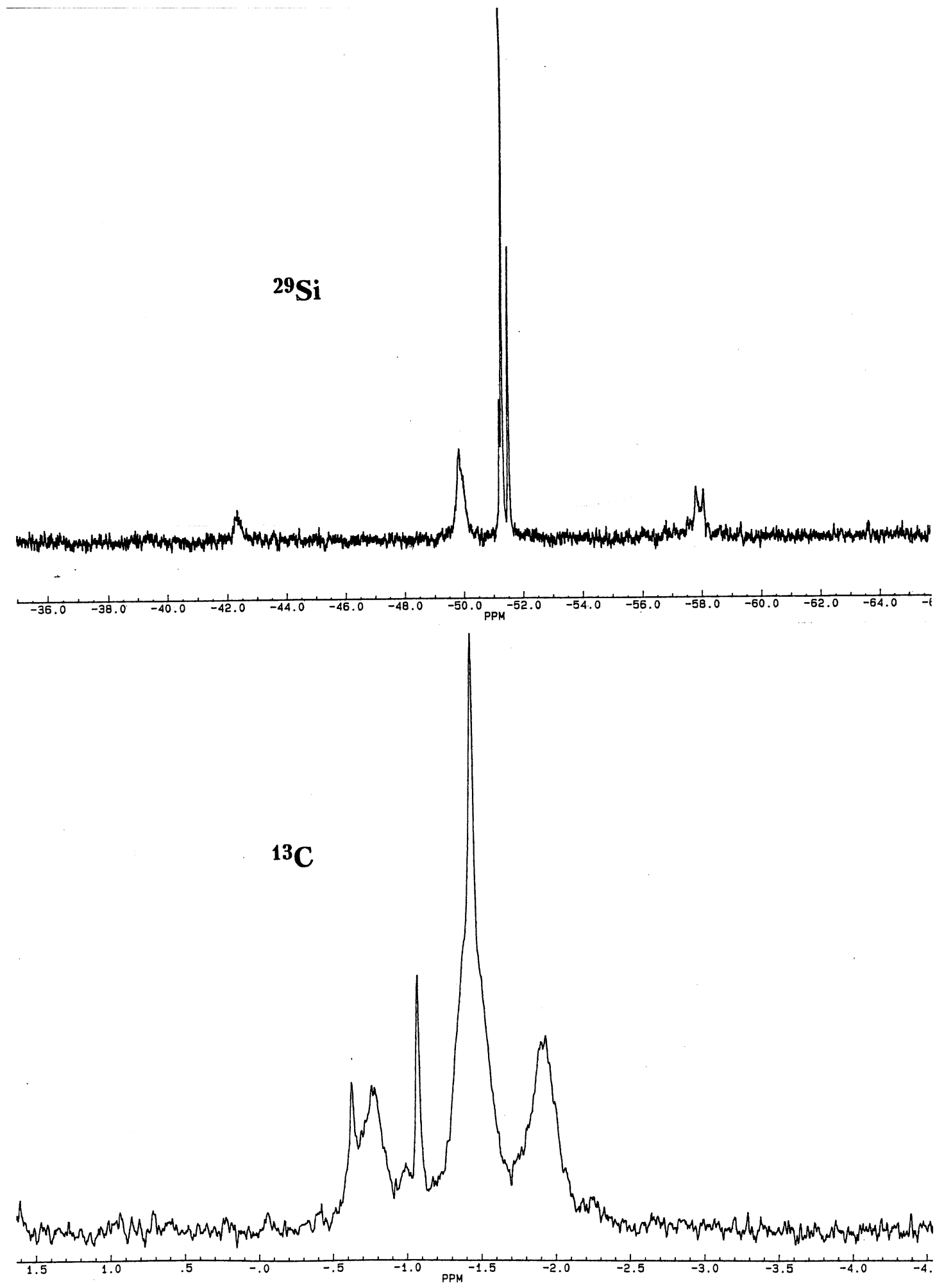

Fig. $2 .{ }^{29} \mathrm{Si}$ (top) and ${ }^{13} \mathrm{C}$ (bottom) $\mathrm{NMR}$ spectra for $\mathrm{Na}\left[\mathrm{O}(\mathrm{HO})_{2} \mathrm{SiMe}\right]$ (ABCR). 


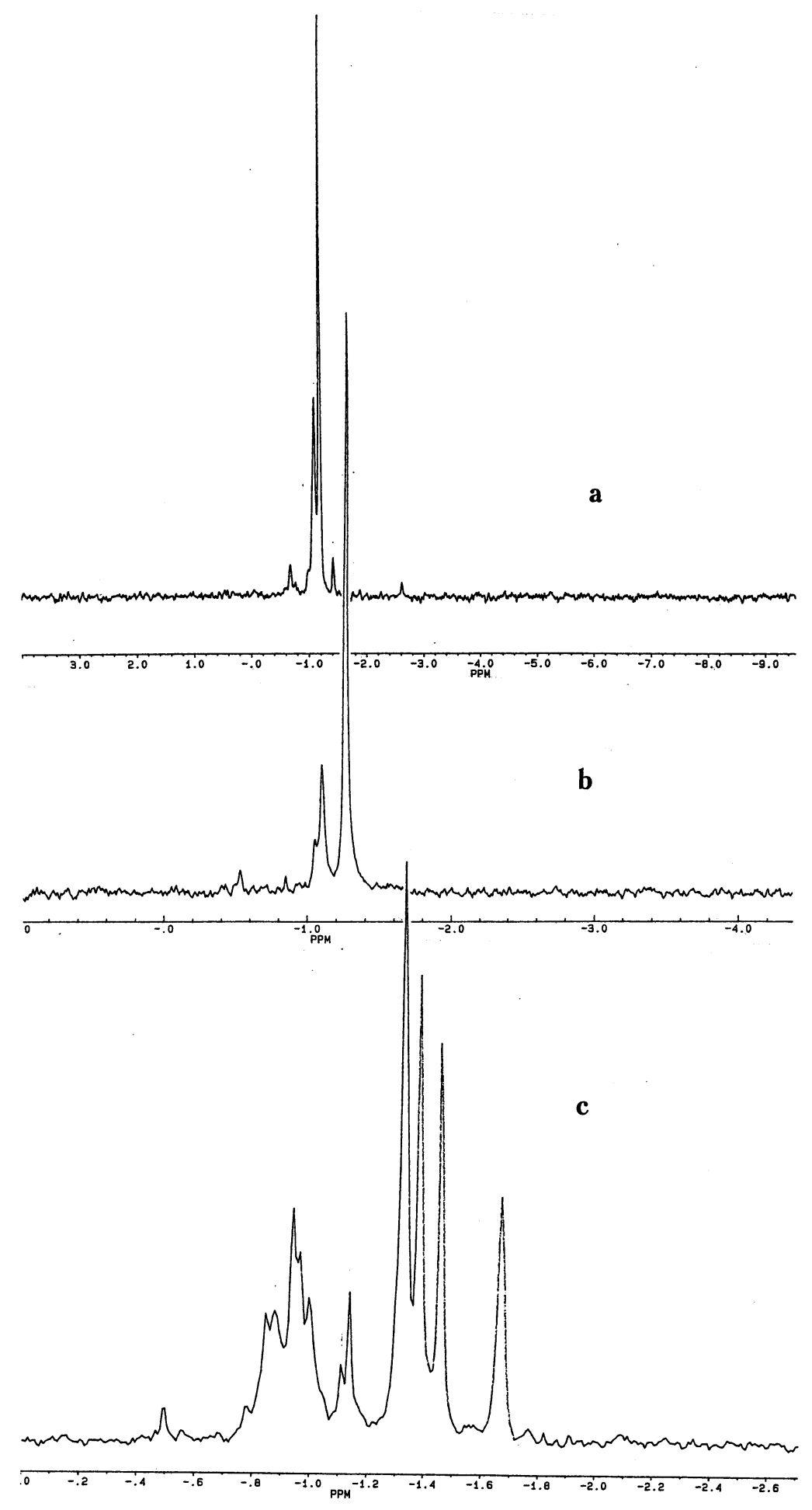

Fig. $3 .{ }^{13} \mathrm{C}$ NMR spectra for $\mathrm{K}_{3}\left[\mathrm{O}_{3} \mathrm{SiMe}\right]$ and $\mathrm{K}\left[\mathrm{O}(\mathrm{HO})_{2} \mathrm{SiMe}\right]$ solutions. a: $\mathrm{K}_{3} \mathrm{O}_{3} \mathrm{SiMe}$ solution prepared immediately after hydrolysis of MTES; b: the same solution after distillation of ethanol; $\mathbf{c}$ : $\mathrm{K}\left[\mathrm{O}(\mathrm{HO})_{2} \mathrm{SiMe}\right]$ solution after heating. 


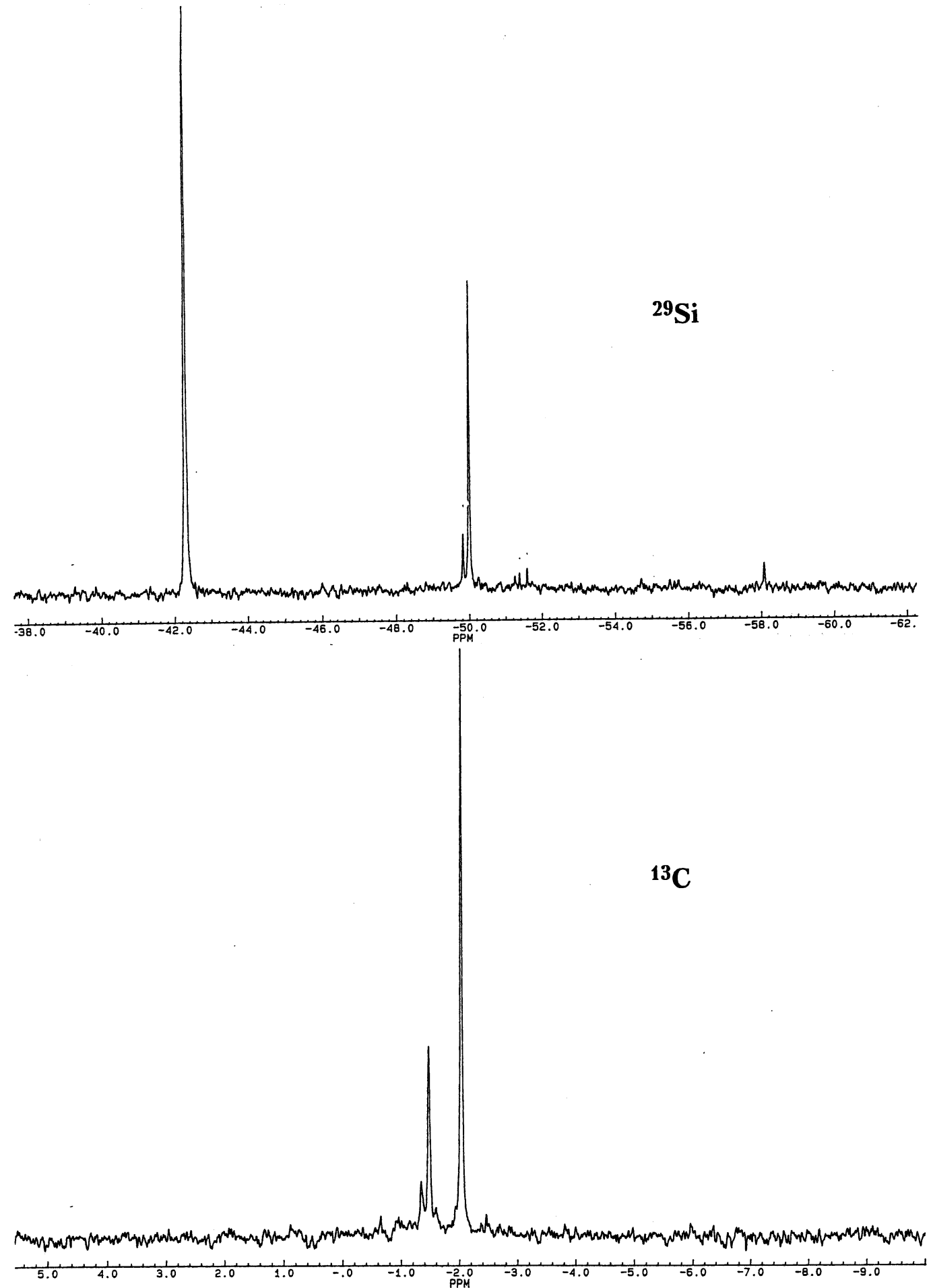

Fig. $4 .{ }^{29} \mathrm{Si}$ (top) and ${ }^{13} \mathrm{C}$ (bottom) NMR spectra for a solution containing $\mathrm{ZrOCl}_{2}$ and $\mathrm{K}_{3}\left[\mathrm{O}_{3} \mathrm{SiMe}\right]$ at a molar ratio of 1:4. 


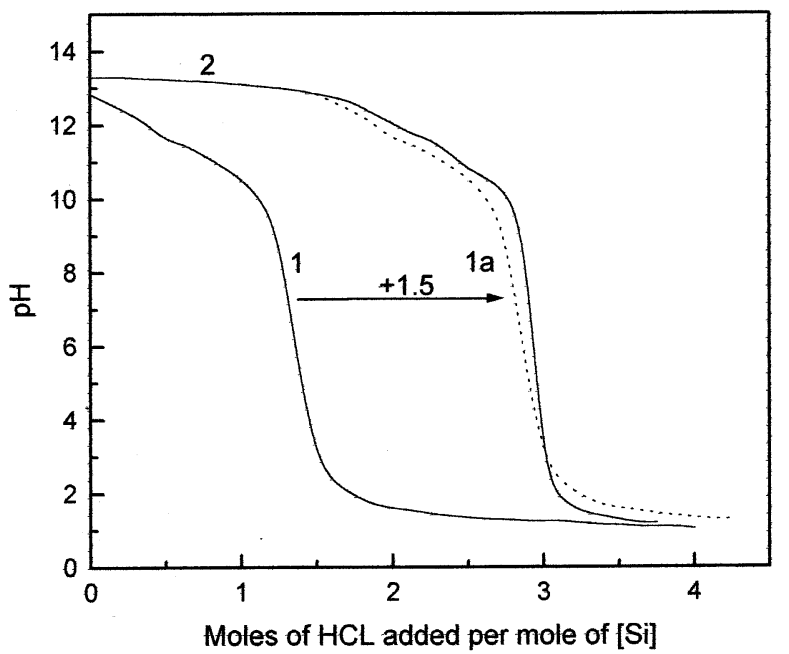

Fig. 5. pH-metric titration of solutions (listed below) with $1 \mathrm{M}$

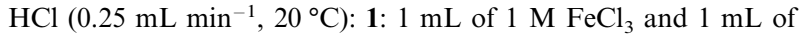
$2 \mathrm{M} \mathrm{K}_{3}\left[\mathrm{O}_{3} \mathrm{SiMe}\right]$ diluted with $20 \mathrm{~mL}$ of water; $2: 1 \mathrm{~mL}$ of $2 \mathrm{M}$ $\mathrm{K}_{3}\left[\mathrm{O}_{3} \mathrm{SiMe}\right]$ diluted with $20 \mathrm{~mL}$ of water.

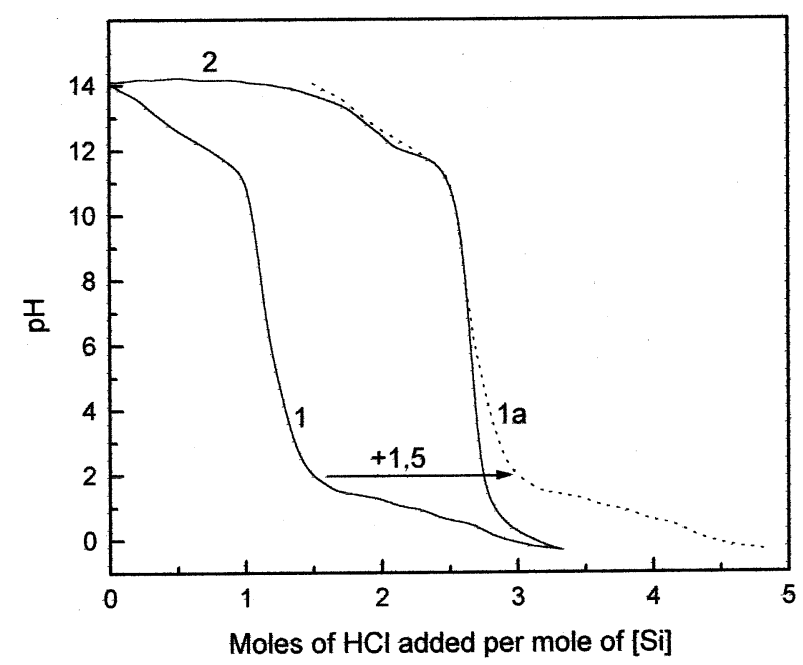

Fig. 6. pH-metric titration of solutions (listed below) with $5 \mathrm{M}$ $\mathrm{HCl}\left(0.25 \mathrm{~mL} \mathrm{~min}^{-1}, 20^{\circ} \mathrm{C}\right): 1: 6 \mathrm{~mL}$ of $1 \mathrm{M} \mathrm{FeCl}_{3}$ and $6 \mathrm{~mL}$ of $2 \mathrm{M} \mathrm{K}_{3}\left[\mathrm{O}_{3} \mathrm{SiMe}\right]$ without dilution; 2: $6 \mathrm{~mL}$ of $2 \mathrm{M} \mathrm{K}_{3}\left[\mathrm{O}_{3} \mathrm{SiMe}\right]$ diluted with $6 \mathrm{~mL}$ of water.
Fig. 5 shows curves of the potentiometric titration with a $1 \mathrm{M}$ solution of $\mathrm{HCl}$ plotted for diluted solutions containing methylsiliconate complexes of iron (curve 1) and the initial potassium methylsiliconate (curve 2). It is seen that a sharp transition of $\mathrm{pH}$ from alkaline to sub-acidic (see curve 2) corresponds to $3 \mathrm{~mol}$ of $\mathrm{HCl}$ per $1 \mathrm{~mol}$ of $\mathrm{K}_{3}\left[\mathrm{O}_{3} \mathrm{SiMe}\right]$, i.e. this transition is consistent with the theoretical amount of the acid necessary for protonation of all the $\left[\mathrm{MeSiO}_{3}\right]^{3-}$ groups. In the absence of complexation in the given system (for example in the case of formation of an iron hydroxide gel stabilized due to adsorption of methylsiliconate anions on the surface of the particles). Curve 1 being shifted by 1.5 along the axis of abscissas should coincide with curve 2 . It is seen that there is a marked difference, namely curve 1 differs from curve $\mathbf{2}$ by a more smooth transition of $\mathrm{pH}$. This fact is an additional argument for the existence of methylsiliconate complexes of iron in the given system. It should also be noted that during this titration formation of any precipitate was not observed.

Similar experiments on potentiometric titration were repeatedly carried out using solutions of higher concentrations (Fig. 6). When titrating a concentrated solution of potassium methylsiliconate with a $5 \mathrm{M}$ solution of $\mathrm{HCl}$ (curve 2), the transition of $\mathrm{pH}$ from alkaline to acidic was observed upon introduction of an amount of $\mathrm{HCl}$ which is lower than the theoretical one. Thus, protonation of all the ' $\mathrm{SiO}^{-}$' groups in $12 \mathrm{mmol}$ of potassium methylsiliconate needs $36 \mathrm{mmol}$ of $\mathrm{HCl}$, while the transition of $\mathrm{pH}$ was observed at about 2.6 equivalents of $\mathrm{HCl}$ per equivalent of $\left[\mathrm{MeSiO}_{3}\right]^{3-}$. As in the case of the above-described titration of diluted solutions, curve 1 in Fig. 6 differs from curve 2 by a more smooth transition of the $\mathrm{pH}$. It should also be noted that in the situation with concentrated systems one could already observe formation of a considerable amount of precipitate in the course of titration. Thus, in the case of potassium methylsiliconate (Fig. 6, curve 2)

Table 1

Elemental analysis results and structural-adsorption characteristics of PFMS sorbents

\begin{tabular}{|c|c|c|c|c|c|c|c|c|c|c|}
\hline \multirow[t]{2}{*}{ Sample } & \multirow[t]{2}{*}{$\mathrm{pH}$} & \multicolumn{6}{|c|}{ Element Content, wt $\%$} & \multirow{2}{*}{$\begin{array}{l}\text { Surface area, } S_{\text {sp. }} \text {. } \\
\mathrm{m}^{2} \mathrm{~g}^{-1}\end{array}$} & \multirow{2}{*}{$\begin{array}{l}\text { Volume, } V_{\mathrm{s}} \\
\mathrm{cm}^{3} \mathrm{~g}^{-1}\end{array}$} & \multirow{2}{*}{$\begin{array}{l}\text { Diameter, } d_{\text {eff. }} \text {. } \\
\mathrm{nm}\end{array}$} \\
\hline & & $\mathrm{C}$ & $\mathrm{H}$ & $\mathrm{Si}$ & $\mathrm{Na}$ & $\mathrm{K}$ & $\mathrm{Fe}$ & & & \\
\hline PFMS-A & 2.2 & 5.2 & 3.3 & 23.2 & 1.3 & 0.8 & 15.3 & 390 & 0.190 & 1.9 \\
\hline PFMS-B & 9.0 & 5.8 & 2.8 & 24.4 & 17.3 & 5.1 & 15.0 & 450 & 0.300 & 2.7 \\
\hline
\end{tabular}


the precipitate forms in the course of titration at $\mathrm{pH}$ 12.0-11.7, while in the iron containing systems (curve 1) the precipitate appears at $\mathrm{pH}$ 11.7-10.8. Our calculations show that in both cases neutral $\mathrm{pH}$ values are attained before the complete substitution of the potassium ions for protons occurred. The determined intervals of the $\mathrm{pH}$ values were taken into account when developing procedures for the synthesis. Their application made it possible to prevent non-homogeneous gelation which is quite characteristic of such systems.

However, all attempts to prepare homogeneous gels through acidification of systems containing methylsiliconate complexes of iron did not succeed. Therefore, a study has been made using the joint gelation of solutions of methylsiliconate complexes of iron with additives of liquid glass since such a process yields a positive result. Lowering of the $\mathrm{pH}$ was attained through addition of hydrochloric acid or through treatment with a cation-exchange resin. The salient features of this system revealed when developing the procedures for synthesis are listed below.

Firstly, it is necessary to use highest possible concentrations of initial solutions at which separation of the exhausted cation-exchange resin or uniform mixing of components are still feasible. This inference is in agreement with the familiar data, according to which the spatial structure of xerogel forms faster in the case of concentrated solutions.

Secondly, it has been established that the gelation process for the studied system in a weakly basic medium ( $\mathrm{pH} 9-10)$ proceeds very rapidly (several minutes) and in an acidic medium ( $\mathrm{pH} \mathrm{2-3)} \mathrm{substantially} \mathrm{more}$ slowly (several hours). In this situation, even a slight dilution of a reaction mixture with water strongly retards the gelation. But since such an effect was also exerted by cooling the starting materials, in view of the above-mentioned, a use was made of the latter.

Thirdly, when preparing homogeneous gels, we use the maximum content of complexed iron. By experiment it has been found that the optimum molar ratio of 'organic' silicon/'inorganic' silicon is 1:1 (in this case the total atomic ratio silicon/iron is 4:1). All the attempts to prepare homogeneous gels at lower contents of liquid glass (of 'inorganic' silicon) were unsuccessful.

As it has been already mentioned, the necessary decrease in the $\mathrm{pH}$ values was attained both by treatment of the solution with a cation-exchange resin and by a direct acidification with hydrochloric acid. Although the system with a final pH 2.2 (PFMS-A) reacts rather slowly (for several hours), in the course of the synthesis it passes through a range of $\mathrm{pH}$ values (pH 9-10) favorable for rapid gelation. As a consequence, the change in the conditions (concentration
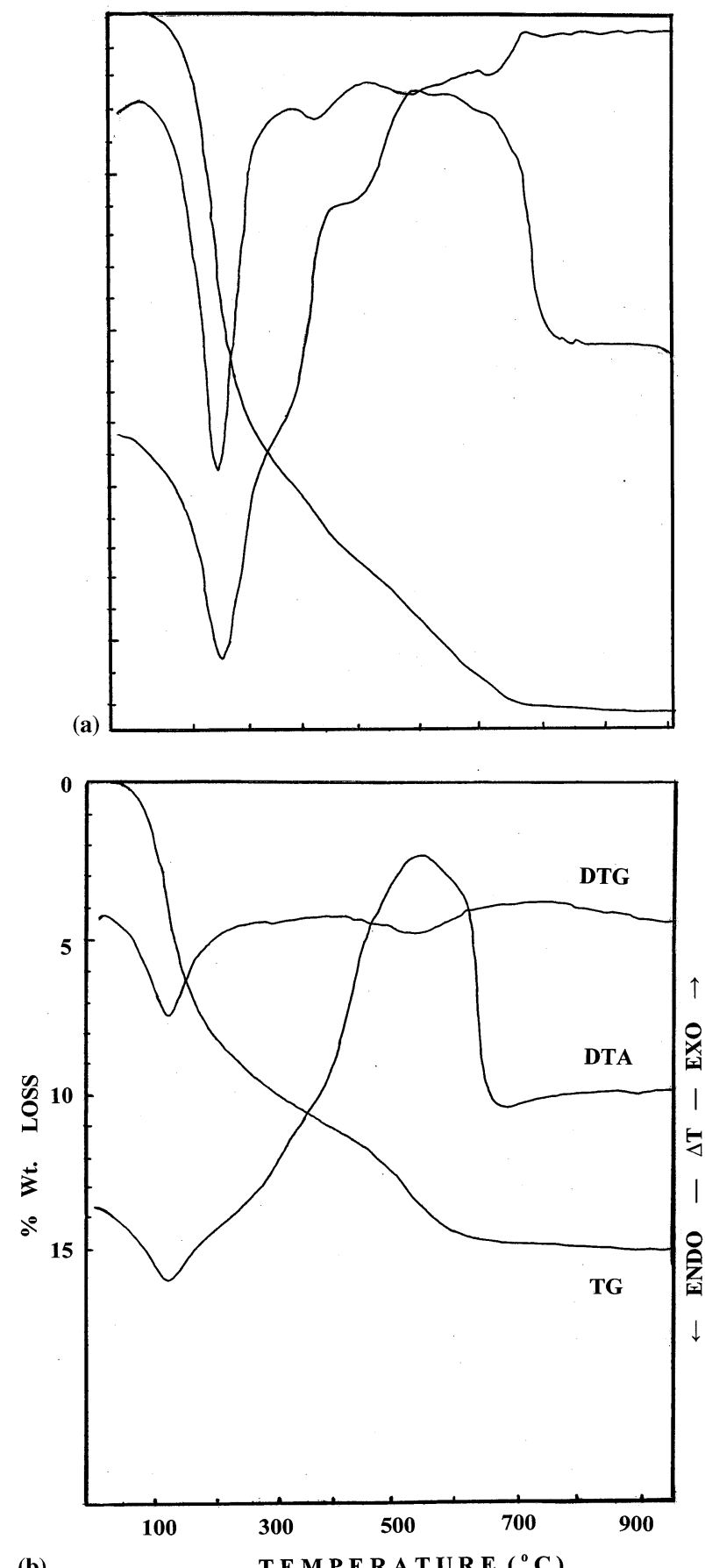

(b)

Fig. 7. Curves of the thermal analysis for samples of PFMS-A (a) and PFMS-B (b). 
and temperature) used in the procedure for the synthesis of PFMS-A leads to gelation already, before separation of resin KU-2. The utilization of this resin for the preparation of PFMS-B, i.e. for the synthesis in an alkaline medium, practically did not make it possible to achieve reproducible and reliable results even with a variation in the scale of the synthesis. Therefore, we attempted a direct acidification of the reaction mixture with hydrochloric acid under conditions of an intense cooling of the starting materials in order to avoid local self-heating and gelation during mixing.
Keeping in mind the above points, we have developed procedures for production of homogeneous gels in an alkaline (PFMS-B) and acidic (PFMS-A) media that are described in detail in the experimental section. The xerogels prepared through treatment with $1 \mathrm{M}$ solution of $\mathrm{HCl}$ lose their iron slowly (for $24 \mathrm{~h}$ ) and become colorless.

From the analysis of the data listed in Table 1 it can be seen that the main part of the iron(III) complexes do not decompose when the gels are treated with the aim to prepare xerogels. The formula index ' $x$ ' (see Scheme (3)) is more close to its

Table 2

Data of the thermal analysis of the PFMS sorbents

\begin{tabular}{|c|c|c|c|c|}
\hline \multirow[t]{2}{*}{ Sample } & \multicolumn{2}{|l|}{ Water, wt $\%$} & \multicolumn{2}{|c|}{ Organic Part, wt $\%$} \\
\hline & Theoretical $^{\mathrm{a}}$ & Experimental & Theoretical $^{\mathrm{a}}$ & Experimental \\
\hline PFMS-A & 17.8 & 14.9 & 6.5 & 7.4 \\
\hline PFMS-B & 10.3 & 9.3 & 7.4 & 6.2 \\
\hline
\end{tabular}

${ }^{a}$ From the results of the elemental analysis.

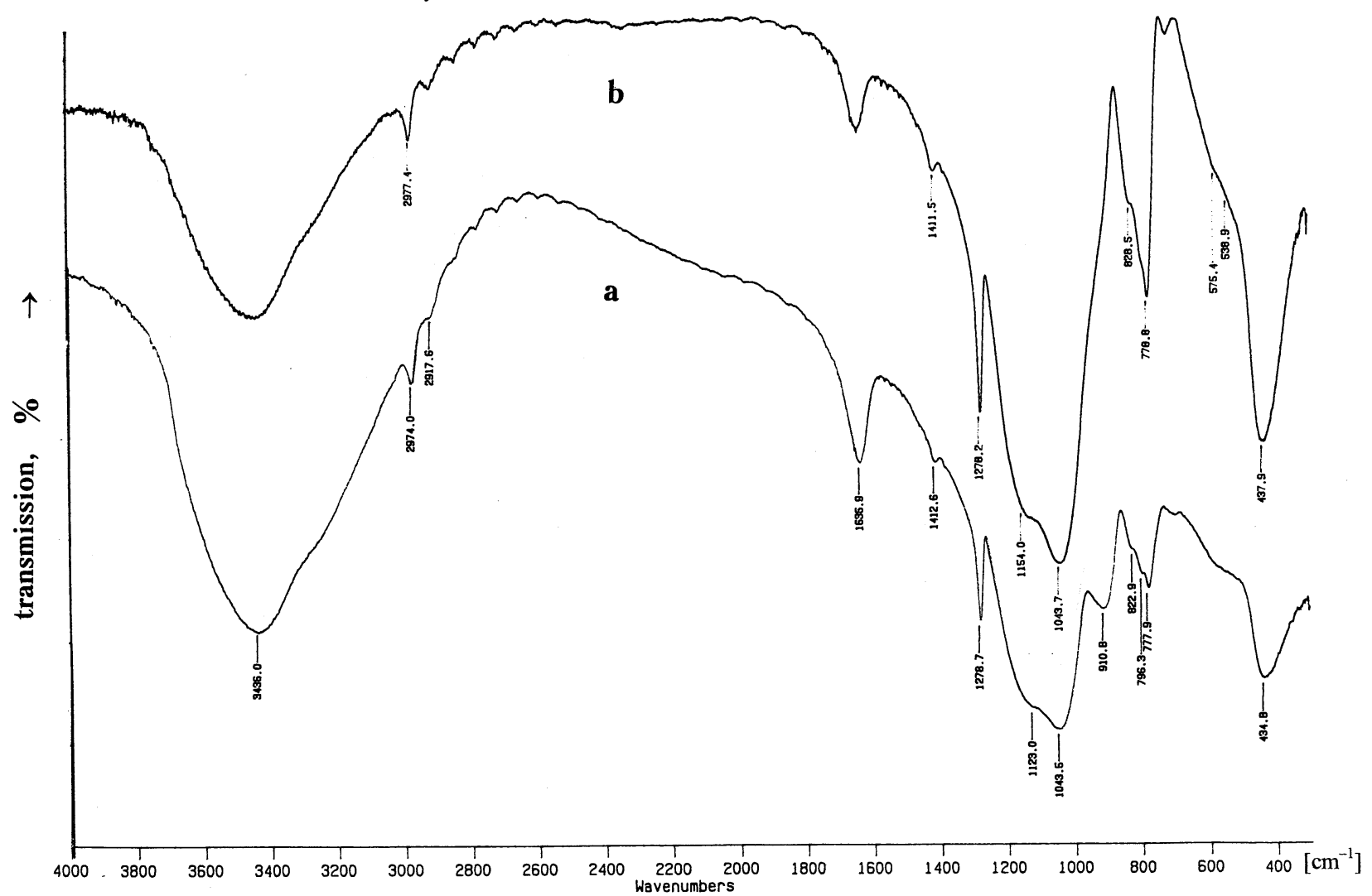

Fig. 8. Infrared spectra of PFMS-A, a, and PFMS-B, b. 


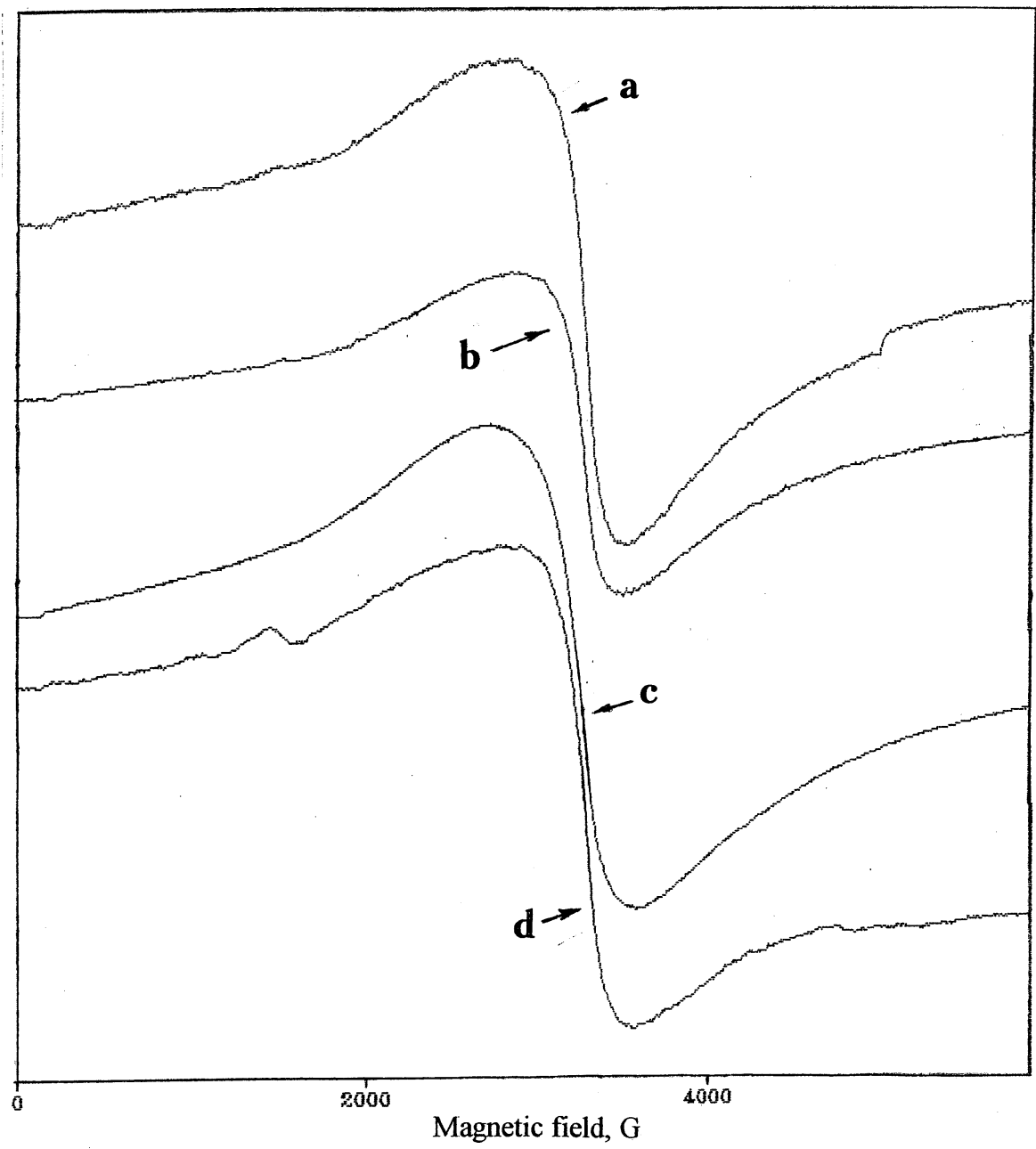

Fig. 9. EPR spectra (77 K): a: solution containing iron(III) complexes; $\mathbf{b}$ : the same solution with an additive of liquid glass; $\mathbf{c}$ : xerogel PFMS-A; d: xerogel PFMS-B.

theoretical value 2 in the case of PFMS-B (1.8) than in the case of PFMS-A (1.6). Proceeding from the atomic ratio $\mathrm{C}: \mathrm{Si}: \mathrm{Fe}$ obtained on the basis of the elemental analysis data (1.8:3.2:1.0 for PFMS-B and 1.6:3.0:1.0 for PFMS-A) it is possible to infer that washing leads to loss of both 'inorganic' silicon and 'organic' silicon but the loss of the latter is much lower. It should be also noted that the amount of potassium in the PFMS-B sample turned to be onethird as much as the theoretical amount. In addition, the water content of the sample prepared in an acidic medium (PFMS-A) is higher than that of the PFMSB sample.

The above-mentioned results are in good agreement with the thermal analysis of the synthesized sorbents. Firstly, over the temperature interval 20 $1000{ }^{\circ} \mathrm{C}$, for both the samples one can observe an endothermic effect related to the loss of water (Fig. 7). The mass loss for PFMS-A and PFMS-B amounts to 14.9 and $9.3 \%$, respectively, which is close to the theoretically calculated value (see Table 2). Secondly, in air both the samples suffer decarbonization $\left(T_{\max }=485^{\circ} \mathrm{C}\right.$ (PFMS-A) and $T_{\max }=$ $553{ }^{\circ} \mathrm{C}$ (PFMS-B)). The mass loss corresponds to the complete oxidation of organic parts of the samples and is close to the theoretically calculated value (Table 2).

Our analysis of the IR spectra made it possible to draw the following conclusions. Both materials have a polyorganosiloxane skeleton, which is evidenced by 
the appearance of the characteristic intense absorption band at $1044 \mathrm{~cm}^{-1}$ with a well-defined shoulder at $1123 \mathrm{~cm}^{-1}$ in the IR spectrum for PFMS-A and PFMS-B (Fig. 8)[32]. The absorption bands at 1279 and $1413 \mathrm{~cm}^{-1}$ in the case of PFMS-A and at 1278 and $1412 \mathrm{~cm}^{-1}$ in the case of PFMS-B are ascribed to the $\delta_{\mathrm{s}}$ and $\delta_{\text {as }}$ vibrations of methyl groups linked with silicon atoms[33]. Besides, at higher wave numbers of the spectrum there appears a well-defined band at 2918 and $2974 \mathrm{~cm}^{-1}$ (PFMS-A) or 2920 and $2977 \mathrm{~cm}^{-1}$ (PFMS-B) assigned to the $v_{\mathrm{s}}$ and $v_{\text {as }} \mathrm{C}-\mathrm{H}$ vibrations of these groups. Water, contained in both the samples, gives rise to a broad and intense absorption band at $3436 \mathrm{~cm}^{-1}$ related to valence vibrations of $\mathrm{O}-\mathrm{H}$ bonds as well as a middle-intensity band at $1637 \mathrm{~cm}^{-1}$ related to the $\delta-\left(\mathrm{H}_{2} \mathrm{O}\right)$ (see Fig. $8)$. On the whole, it should be noted that the IR spectra of both the samples are very similar.

The EPR spectra of both starting solutions and the synthesized xerogels exhibit a practically single intense signal with $g \sim 2.00$ (Fig. 9). The $g=2.0$ resonance has been interpreted as due to either octacoordinated $\mathrm{Fe}$ (III) or clusters of Fe(III) ions coupled by strong spin-spin interaction [34]. In this study the presence of a strong interactive (though broad) effect at $g \sim 2.00$ indicates that this effect may be due to the presence of octahedral Fe(III) rather than due to spin-spin interactions of iron.

The isotherms of adsorption-desorption of nitrogen for PFMS-B is shown in Fig. 10, and the parameters of the pore structure are listed in Table 1. The presence of a hysteresis loop for the relative pressure in the range of $0.4-0.6$ points to the existence of a mesoporous structure of PFMS-B. This inference is corroborated by the magnitude of values of the mean pore diameter. As it can be seen from Table 1, the higher specific surface is characteristic of the sample prepared in an alkaline medium.

\section{Conclusion}

Thus, the studies presented here provide evidence for the fact that methylsiliconate anions form strong complexes with cations of trivalent iron and these complexes are stable in a highly alkaline medium. With decreasing $\mathrm{pH}$ the polycondensation occurs that proceeds most rapidly at $\mathrm{pH} \mathrm{9-10} \mathrm{and} \mathrm{substan-}$ tially slower in an acidic medium $(\mathrm{pH} 2-3)$. In the presence of additives of liquid glass at certain con-

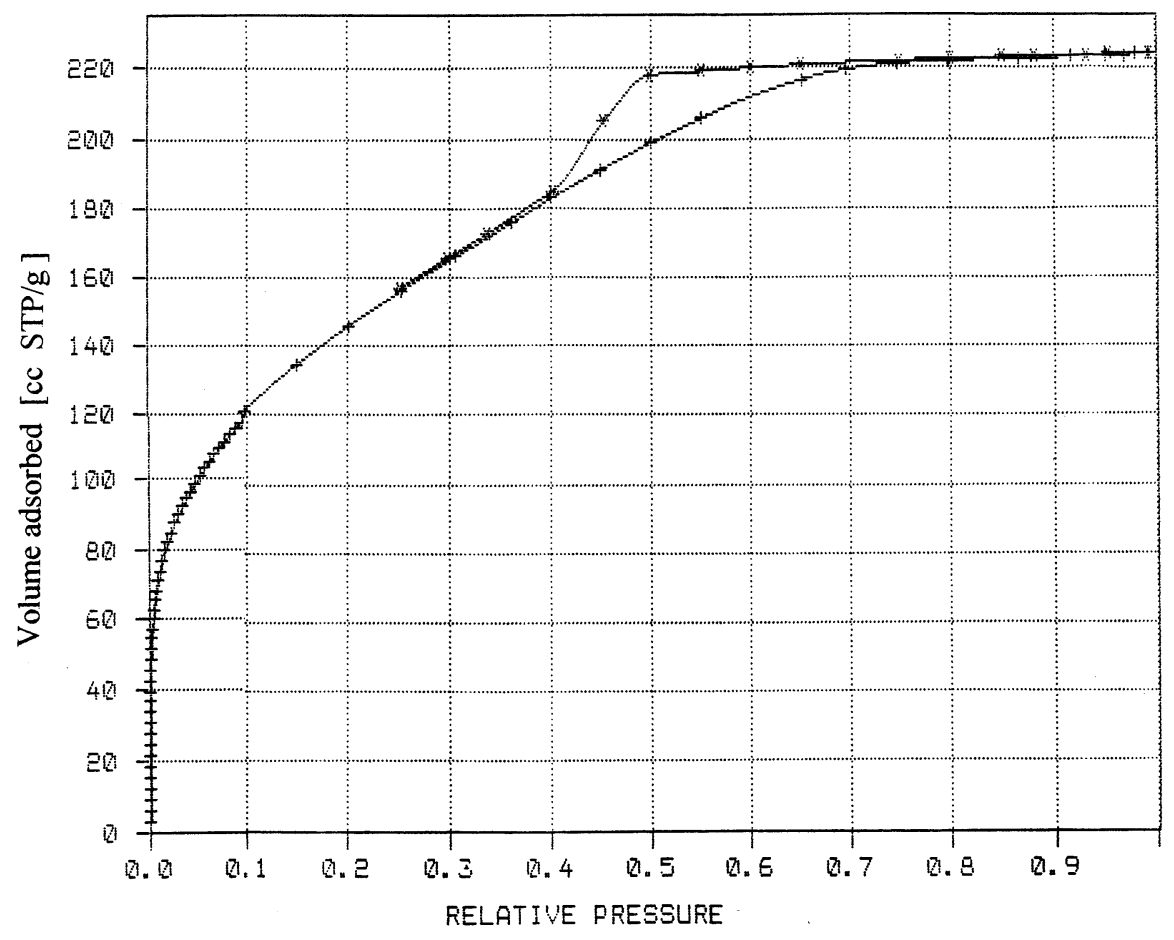

Fig. 10. Adsorption-desorption isotherms of $\mathrm{N}_{2}$ plotted for PFMS-B (+: ads; *: des). 
centration and temperature the polycondensation leads to formation of homogeneous polyferromethylsiloxane gels. Unlike the results of a number of preceding studies in this field [16-21], the approach developed here makes it possible to synthesize polyferromethylsiloxane sorbents having a considerably high transition metal content. Furthermore, these sorbents possess a mesoporous structure and high specific surface area. In principle, this approach can also be employed in the synthesis of mesoporous xerogels based on a variety of polyvalent transition metal alkylsiliconates.

\section{Acknowledgements}

H.W.R. thanks the Deutsche Forschungsgemeinschaft for the financial support of this work. Y.L.Z would like to express his sincere gratitude to DAAD and R.M. to AvH Foundation for research fellowships. Thanks are also due to Dr. T. N. Yakubovich and Dr. V.V. Teslenko for recording EPR spectra, and to Dr. O.V. Melezhyk for participation in fruitful discussions.

\section{References}

[1] R.K. Iler, The Chemistry of Silica: Solubility, Polymerization, Colloid and Surface Properties, and Biochemistry, Wiley-Interscience, New York, 1979.

[2] I.E. Neimark, R.Yu. Sheinfain, Silica Gel: Preparation, Properties, and Uses (in Russian), Naukova Dumka, Kiev, 1973.

[3] I.E. Neimark, Synthetic Mineral Adsorbents and Catalyst Supports (in Russian), Naukova Dumka, Kiev, 1982.

[4] V.S. Komarov, I.B. Dubnitskaya, Physico-Chemical Foundations for Regulation of Porous Structures of Adsorbents and Catalysts (in Russian), Nauka i Tekhnika, Minsk, 1981.

[5] N.F. Ermolenko, M.D. Efros, Regulation of Porous Structures of Oxide Adsorbents and Catalysts (in Russian), Nauka i Tekhnika, Minsk, 1971.

[6] V.A. Dzis'ko, A.P. Karnaukhov, D.V. Tarasova, PhysicoChemical Foundations for Synthesis of Oxide Catalysts (in Russian), Novosibirsk, Nauka, 1978.

[7] G.V. Lisichkin, in: G.V. Lisichkin (Ed.), Chemically Modified Silica in Sorption, Catalysis, and Chromatography (in Russian), Khimiya, Moscow, 1986.

[8] V.A. Tertykh, L.A. Belyakova, Chemical Reactions with the Participation of Silica Surface (in Russian), Naukova Dumka, Kiev, 1991.

[9] (a)V.N. Zaitsev, Complexing Silicas: Synthesis, Structure of the Attached Layer and Chemistry of Surface, Khar'kov: Folio, 1997 (in Russian); (b) Yu.V. Kholin, V.N. Zaitsev,
Complexes on the Surface of Chemically Modified Silicas, Folio, Khar'kov, 1997 (in Russian).

[10] M. Suzuki, Adsorption Engineering, Elsevier, Amsterdam, 1990.

[11] C.J. Brinker, G. Scherer, Sol-Gel Science. The Physics and Chemistry of Sol-Gel Processing, Academic Press, New York, 1989.

[12] Yu.L. Zub, R.V. Parish, Stud. Surf. Sci. Catal. 99 (1996) 285.

[13] M.G. Voronkov, N.N. Vlasova, Yu.N. Pozhidaev, Zh. Prikl. Khim. (S.-Petersburg) 69 (1996) 705, CA 125: 330696d

[14] I.B. Slinyakova, T.I. Denisova, Organosilicon Adsorbents: Preparation, Properties, Application,(in Russian), Naukova Dumka, Kiev, 1988.

[15] M.G. Voronkov, E.A. Maletina, V.K. Roman, Heteropolysiloxanes (in Russian), Novosibirsk, Nauka, 1984.

[16] I.M. Samodumova, I.B. Slinyakova, L.I. Kiseleva, Kolloidn. Zh. 38502 CA 85 (1976) 131018g.

[17] I.M. Samodumova, I.B. Slinyakova, I.P. Lemesh, A.K. Matkovsky, Kolloidn. Zh. 411203 CA 92 (1979) 82977k.

[18] L.I. Kiseleva, I.M. Samodumova, I.B. Slinyakova, Kolloidn. Zh. 45 323CA 98 (1983) 186210v.

[19] I.M. Samodumova, Teor. Eksp. Khim. 19 748; CA 100 (1983) 69069e.

[20] L.I. Kiseleva, I.M. Samodumova, L.N. Prikhod'ko, Yu.N. Shevchenko, Ukr. Khim. Zh. 55 (1989) 366; CA 111: 181440x

[21] L.I. Kiseleva, I.M. Samodumova, L.N. Prikhod'ko, Zh. Fiz. Khim. 64 2400; CA 114 (1990) 69627z.

[22] A.K. Matkovsky, Ph.D. Thesis (in Russian), Institute of Physical Chemistry of NAS of Ukraine, Kiev, 1992.

[23] R. Murugavel, F. Voigt, M.G. Walawalkar, H.W. Roesky, Chem. Rev. 96 (1996) 2205.

[24] M.G. Walawalkar, R. Murugavel, H.W. Roesky, in: R. Corriu, P. Jutzi (Eds.), Tailor-Made Silicon-Oxygen Compounds: From Molecules to Materials, Vieweg, Braunschweig/Wiesbaden, 1996, p. 61.

[25] V.S. Kulikova, M.M. Levitsky, A.L. Buchachenko, Izv. RAN, Ser. Khim. 3021; CA 126 (1996) 263685e.

[26] U. Ritter, N. Winkhofer, H.-G. Schmidt, H.W. Roesky, Angew. Chem. Int. Ed. Engl. 35 (1996) 524.

[27] A.A. Zhdanov, M.M. Levitskii, A.Yu. D'yakonov, O.I. Shchegolikhina, A.D. Kolbanovsky, R.A. Stukan, A.G. Knizhnik, A.L. Buchachenko, Izv. Akad. Nauk. SSSR, Ser. Khim. 2512; CA 114 (1990) 155929f.

[28] A. Cornia, A.C. Fabretti, D. Gatteschi, G. Palyi, E. Rentschler, O.I. Shchegolikhina, A.A. Zhdanov, Inorg. Chem. 34 (1995) 5383.

[29] J.S. Brunauer, P.H. Emmet, E. Teller, J. Am. Chem. Soc. 60 (1938) 309.

[30] E.P. Barrett, L.G. Joyner, P.P. Halenda, J. Am. Chem. Soc. 73 (1951) 373.

[31] H. Marsmann, in: P. Diehl, E. Fluck, R. Kosfeld (Eds.), NMR. Basic Principles and Progress, Springer-Verlag, 17, Berlin, 1981, p. 65.

[32] L.P. Finn, I.B. Slinyakova, Kolloidn. Zh. 37 723; CA 83 (1975) $164975 \mathrm{~m}$.

[33] V. Raman, O.P. Bahn, N.K. Jha, J. Mater. Sci. Lett. 12 (1988) 1188.

[34] S. Roy, D. Ganguli, J. Non-Cryst. Solids 195 (1996) 38. 